ORIGINAL ARTICLE

\title{
Unruptured Cerebral Aneurysms Presenting with Ischemic Events
}

\author{
Nancy McLaughlin, Michel W. Bojanowski
}

\begin{abstract}
Background: Patients harboring an unruptured cerebral aneurysm may present with ischemic events. The goal of this study is to assess the clinical and radiological characteristics and the outcome following treatment of these patients. Methods: The study population included 463 patients with unruptured cerebral aneurysms treated between January 2000 and November 2006 . Patients with aneurysms manifesting with ischemic events were included. Outcome was assessed 12 months following aneurysm treatment using the modified Rankin scale. Results: Eleven patients were included in this series. An acute ischemic lesion in the symptomatic territory was demonstrated in six patients. The aneurysms were located on the internal carotid artery $(n=4)$, middle cerebral artery $(\mathrm{n}=4)$, superior cerebellar artery $(n=2)$ and basilar artery $(n=1)$. They measured $10 \mathrm{~mm}$ or less $(n=7) ; 11-20 \mathrm{~mm}(n=2)$; more than $21 \mathrm{~mm}(\mathrm{n}=2)$. Five aneurysms were partially thrombosed on imaging. Five patients were referred for coiling. Of these, one patient had an unsuccessful coiling attempt, one had a residual neck, and three presented an aneurysm recurrence. Six patients were treated surgically. Symptomatic thromboembolism occurred after surgery in three patients. Complete aneurysm exclusion was documented in five of six operated patients. Nine of the ten treated patients had a favorable outcome. Conclusion: Even though aneurysms presenting with ischemic events are often small and located on the anterior circulation, in this series the risk of thromboembolic events following aneurysm treatment is noteworthy. This information is relevant given the possible benign natural history in terms of stroke and risk of bleeding for some of these aneurysms.
\end{abstract}

RÉSUMÉ: Événements ischémiques comme premières manifestations d'anévrismes cérébraux non rompus. Contexte : Il arrive que des patients qui ont un anévrisme cérébral non rompu consultent pour un événement ischémique. Le but de cette étude était de décrire les caractéristiques cliniques et radiologiques de ces patients ainsi que le résultat de leur traitement. Méthodes : La population étudiée était constituée de 463 patients porteurs d'un anévrisme cérébral non rompu, traités entre janvier 2000 et novembre 2006. Les patients chez qui la manifestation de l'anévrisme était un événement ischémique ont été inclus dans l'étude. Le résultat était évalué 12 mois après le traitement de l'anévrisme au moyen de la Modified Rankin Scale. Résultats : Onze patients ont été inclus dans l'étude. Une lésion ischémique aiguë dans le territoire symptomatique a été démontrée chez six patients. L'anévrisme était localisé à la carotide interne $(n=4)$, à l'artère cérébrale moyenne $(n=4)$, à l'artère cérébelleuse supérieure $(n=2)$ et au tronc basilaire $(\mathrm{n}=1)$. Il mesurait $10 \mathrm{~mm}$ ou moins $(\mathrm{n}=7) ; 11-20 \mathrm{~mm}(\mathrm{n}=2)$; plus de $21 \mathrm{~mm}(\mathrm{n}=2)$. L'imagerie a démontré que cinq anévrismes étaient partiellement thrombosés. Cinq patients ont été dirigés en neuroradiologie pour un traitement endovasculaire. Ce traitement s'est soldé par un échec chez un patient, le col de l'anévrisme a persisté chez un patient et on a observé une récidive de l'anévrisme chez trois patients. Six patients ont subi une chirurgie. Trois patients ont présenté une thromboembolie symptomatique après la chirurgie. Une exclusion complète de l'anévrisme a été constatée chez cinq des six patients opérés. Neuf des dix patients traités ont eu une évolution favorable. Conclusion : Bien que les anévrismes cérébraux dont la première manifestation est un événement ischémique soient souvent de petite taille et localisés à la circulation antérieure, dans cette série de cas le risque d'événements thromboemboliques après le traitement de l'anévrisme n'est pas négligeable. Cette information est importante étant donné que certains de ces anévrismes ont une histoire naturelle qui peut être bénigne quant à l'accident vasculaire cérébral et au risque de saignement.

Can. J. Neurol. Sci. 2008; 35: 588-592

Intracranial aneurysms uncommonly present with transient ischemic attacks (TIAs) or ischemic strokes. Thrombotic material within the aneurysm may embolize to distal vessels or the thrombus can extend from the aneurysmal sac into the parent artery's lumen. ${ }^{1-3}$ The natural history of unruptured intracranial aneurysms presenting with ischemic symptoms remains unknown. ${ }^{4,5}$ Therefore, no consensus regarding the management of such aneurysms exists. Aneurysm surgery could alleviate subsequent strokes and prevent subarachnoid hemorrhages (SAH). ${ }^{6}$ However, it is believed that this procedure is associated with a higher risk of intraoperative thromboembolic events in comparison to asymptomatic aneurysms..$^{1,7,8}$ On the other hand, the efficacy and safety of endovascular strategies in the treatment of such aneurysms is lacking. The goal of this study is

From the Division of Neurosurgery, Department of Surgery, Centre hospitalier de l'Université de Montréal - Hôpital Notre-Dame, Montreal, QC, Canada.

Received November 30, 2007. Final Revisions Submitted April 18, 2008. Correspondence to: Michel W. Bojanowski, Neurosurgery Division, CHUM-Hôpital Notre-Dame, 1560 Sherbrooke St. East, Montreal, Quebec, Canada, H2L 4M1. 
to assess the clinical and radiological characteristics of these patients and their long-term outcome following treatment by endovascular or surgical means.

\section{Methods}

We retrospectively reviewed consecutive patients treated for unruptured cerebral aneurysms at the Centre hospitalier de l'Université de Montreal between January 2000 and November 2006. Factors considered in the treatment decision were patientrelated factors including age, comorbidities, prior hemorrhage from another aneurysm, personal choice and the aneurysm's characteristics including size, location and morphology. During this study period, 463 patients with unruptured cerebral aneurysms were treated at our institution, approximately $30 \%$ by surgical means and $70 \%$ by endovascular means. Since the International Subarachnoid Trial results, embolisation has been the main proposed treatment option for unruptured aneurysms when safely feasible. Surgery has usually been reserved for aneurysms not favorable for endovascular treatment.

In the study population we included patients satisfying the following inclusion criteria suggested by Cohen $\left.{ }^{9}: 1\right)$ the presence of a clinical TIA or completed stroke; 2) the documentation of an aneurysm by angiography in the vascular territory corresponding to the acute symptomatology; 3) no other cause that could

Table: Patient and aneurysm characteristics and treatment results

\begin{tabular}{|c|c|c|c|c|c|c|c|}
\hline \multirow{2}{*}{$\begin{array}{c}\text { Patient } \\
\text { No. }\end{array}$} & \multirow{2}{*}{$\begin{array}{l}\text { Sex; } \\
\text { Age }\end{array}$} & \multicolumn{3}{|c|}{ Aneurysm characteristics } & \multirow{2}{*}{$\begin{array}{c}\text { Treatment } \\
\text { modality }\end{array}$} & \multirow{2}{*}{$\begin{array}{l}\text { Treatment } \\
\text { results }\end{array}$} & \multirow{2}{*}{$\begin{array}{c}\text { Outcome } \\
\left(\mathrm{MRS}^{2}\right)\end{array}$} \\
\hline & & Site $^{1}$ & $\begin{array}{l}\text { Size } \\
\text { (in } \\
\text { mm) }\end{array}$ & $\begin{array}{l}\text { Partial } \\
\text { Thrombosis }\end{array}$ & & & \\
\hline 1 & M; 68 & Left ICA & 27 & Yes & Endovascular & $\begin{array}{l}\text { Aneurysm recurrence; } \\
\text { Re-embolization }\end{array}$ & 0 \\
\hline 2 & $\mathrm{M} ; 53$ & $\begin{array}{l}\text { Right } \\
\text { MCA }\end{array}$ & 25 & Yes & Endovascular & $\begin{array}{l}\text { Aneurysm recurrence; } \\
\text { Re-embolization }\end{array}$ & 0 \\
\hline 3 & M; 49 & $\begin{array}{l}\text { Right } \\
\text { SCA }\end{array}$ & 10 & Yes & Endovascular & $\begin{array}{l}\text { Residual neck } \\
\text { Re-embolization }\end{array}$ & 1 \\
\hline 4 & $\mathrm{M}, 45$ & $\begin{array}{l}\text { Right } \\
\text { SCA }\end{array}$ & 10 & Yes & Endovascular & $\begin{array}{l}\text { Aneurysm recurrence; } \\
\text { Re-embolization } \\
\text { Thrombosis of the } \\
\text { aneurysm's parent vessel } \\
3 \text { mo after treatment }\end{array}$ & 3 \\
\hline 5 & $\mathrm{M} ; 52$ & $\begin{array}{l}\text { Basilar } \\
\text { tip }\end{array}$ & 12 & No & Endovascular & $\begin{array}{l}\text { Unfavorable for } \\
\text { embolization }\end{array}$ & 2 \\
\hline 6 & $\mathrm{~F} ; 40$ & $\begin{array}{l}\text { Right } \\
\text { ICA }\end{array}$ & 8 & No & Clipping & Complete exclusion & 0 \\
\hline 7 & $\mathrm{M} ; 45$ & $\begin{array}{l}\text { Left } \\
\text { MCA }\end{array}$ & 9 & No & Clipping & Complete exclusion & 0 \\
\hline 8 & $\mathrm{~F}, 37$ & Left ICA & 5 & No & Clipping & Complete exclusion & 0 \\
\hline 9 & $\mathrm{~F} ; 44$ & $\begin{array}{l}\text { Right } \\
\text { MCA }\end{array}$ & 15 & Yes & Clipping & $\begin{array}{l}\text { Residual neck }^{3} \text {; } \\
\text { Symptomatic } \\
\text { thromboembolism } \\
\text { Post-operative day } 17\end{array}$ & 1 \\
\hline 10 & $\mathrm{~F} ; 62$ & $\begin{array}{l}\text { Right } \\
\text { MCA }\end{array}$ & 4- & No & Clipping & $\begin{array}{l}\text { Complete exclusion; } \\
\text { Thrombosis of the } \\
\text { aneurysm's parent vessel } \\
2 \text { mo after surgery }\end{array}$ & 2 \\
\hline 11 & $\mathrm{~F} ; 43$ & Left ICA & 7 & No & Clipping & $\begin{array}{l}\text { Complete exclusion; } \\
\text { Acute symptomatic } \\
\text { thromboembolism } \\
\text { following surgery }\end{array}$ & 2 \\
\hline
\end{tabular}

1. Site: ICA: internal carotid artery; MCA: middle cerebral artery; SCA: superior cerebellar artery; 2. Favorable Modified Rankin Scale: 0-2; Unfavorable Modified Rankin Scale: $\geq 3$; 3 . An aneurysm residue was purposely left to maintain arterial branches permeable; M: Male; F: Female; mo: Months 
produce the ischemic event was documented such as a cardiogenic, hematologic or extracranial arterial source; 4) no clinical or radiographic evidence of recent SAH or vasospasm that could account for the clinical presentation. Patients with a dolichoectatic aneurysm were excluded.

Of the 463 patients with unruptured cerebral aneurysms that were treated during the study period, 152 were discovered in patients who had a previous SAH and 311 were documented without a history of SAH. On admission, all patients were investigated with a cerebral computed tomogram (CT) and/or cerebral magnetic resonance imaging (MRI) and digital substraction angiography (DSA). The primary neurologist and neurosurgeon considered the aneurysm was the origin of the emboli causing the patient's ischemic events.

All patients were considered for exclusion of the aneurysm. The patient's age and comorbidities, the aneurysm's characteristics including location, size and morphology, as well as the patient's choice were taken into consideration to decide the treatment modality.

Functional outcome was obtained by chart review of the follow-up appointment held 12 months after treatment. Both authors independently reviewed the charts and attributed each patient a score on the Modified Rankin Scale (MRS). Favorable outcome was defined as a MRS $\leq 2^{10}$. No disagreement occurred in MRS score attribution.

\section{RESULTS}

Eleven patients $(2.4 \%, 11 / 463)$ were included in this study, six men and five females with a mean age of 48.8 years (range 37-68yrs). High blood pressure was known in four, diabetes in one; hyperlipidemia in two. Six patients experienced a single ischemic event and five had multiple events prior to consultation.

An acute ischemic lesion was found on MRI in the symptomatic vascular territory in six patients. Partial thrombosis of the symptomatic aneurysm was found in five cases (Table). Digital substraction angiography documented a unique aneurysm in five patients and multiple aneurysms in six. Symptomatic aneurysms were located on the internal carotid artery $(n=4)$, the middle cerebral artery (MCA) $(n=4)$, superior cerebellar artery $(\mathrm{SCA})(\mathrm{n}=2)$ and the basilar artery $(\mathrm{n}=1)$. They measured $10 \mathrm{~mm}$ or less $(n=7) ; 11-20 \mathrm{~mm}(n=2) ; 21 \mathrm{~mm}$ or greater $(n=2)$ (Table). Of these 11 patients, five were oriented towards endovascular treatment and six towards surgery (Table). No patient was treated with antiplatelet or anticoagulant medication prior to aneurysm treatment. Of the five aneurysms oriented towards an endovascular treatment, one presented a residual neck and three developed a recurrence, all four requiring re-treatment. Patient no. 4 presented a thromboembolic event three months after retreatment of a large SCA aneurysm residue. The MRI showed recent ischemia in both thalami and right cerebellar peduncle. The angiography revealed thrombosis of right $\mathrm{P} 1$ and right posterior communicating artery at their origin. The patient was treated with antiplatelet medication. The fifth patient treated endovascularly had a basilar tip aneurysm. The cardiac, vascular and blood work-up were within normal limits. While the patient was waiting for the endovascular treatment, he presented an acute heart attack. The endovacular treatment which had been postponed for a few weeks was unsuccessful given the aneurysm's morphology. In the absence of recurrent ischemic event, surgery was not considered at this point. The patient was treated with antiplatelet medication.

Six patients were treated surgically. In this series, three patients treated by surgical means presented a thromboembolic complication $(50 \%, 3 / 6)$. Symptomatic thromboembolism occurred in the acute post-operative period in Patient no. 11. In Patient no. 9, an aneurysmal remnant had been purposely left during surgery to maintain patent arterial branches. Seventeen days after surgery, the patient presented with left side paresthesia. The MRI revealed a distal ischemic lesion in the right parietal lobe and a second ischemic lesion in the right basal ganglia. Angiography showed distal narrowing of the MCA branches. The patient was treated with antiplatelet medication. Patient no. 10 presented two months after surgery with dysphasia and left arm paresis. Thrombosis of the aneurysm's parent vessel was documented on angiography (Table). All operated patients underwent a follow-up angiography which revealed complete aneurysm exclusion in five patients. Nine of the ten treated patients had a favorable long-term outcome with MRS $\leq 2$.

\section{DISCUSSION}

Transient ischemic attacks and ischemic strokes secondary to unruptured intracranial aneurysms are uncommon. Series have reported that between 3 to $11 \%$ of unruptured aneurysms present with ischemic events. ${ }^{3,11,12}$ Although the rate of recurrent events is generally low, ${ }^{3}$ distal embolization or thrombosis of aneurysm parent vessels have the potential for significant morbidity and mortality. ${ }^{2,3,13}$ In our series, 5 of 11 patients had multiple ischemic events prior to consultation. Even though the risk of aneurysm rupture in this context is unknown, in some series it has been reported higher than asymptomatic aneurysms. ${ }^{14}$ Therefore, interpreting the aneurysm as the source of embolization and not merely incidental is important since it differentiates asymptomatic from symptomatic unruptured cerebral aneurysms.

Some authors have suggested that confirming the presence of an aneurysmal thrombus was necessary to establish the causal relationship between the aneurysm and the ischemic events. ${ }^{15}$ Like other authors, it is our experience that the absence of an imaged thrombus does not exclude the presence of a clot within the aneurysmal sac nor the possibility of its subsequent embolization. ${ }^{3,15,16}$ During MRI and DSA, the thromboemboli may have already fragmented or dislodged to smaller vessels beyond the resolution of routine imaging techniques. A residue of a previous mural clot, as documented on histopathological studies by Mehdorn, might account for ischemic events in some patients without documented aneurysmal thrombus. ${ }^{17}$ Indeed, a clot might accentuate fibrin platelet deposits contributing to the risk of thromboembolic events.

Spontaneous partial thrombosis of cerebral aneurysms has been described most often in larger aneurysms. ${ }^{3,17}$ Black and German found that the larger the volume of the aneurysm sac in relation to the cross-sectional area of the neck, the more sluggish the flow within the fundus, which increased the possibility of thrombosis. ${ }^{18}$ Small-sized aneurysms have also been recognized as possible sources of thromboemboli. ${ }^{3,8,13,15,16}$ In our series, 7 of the 11 symptomatic aneurysms measured $10 \mathrm{~mm}$ or less, as measured by MRI. Magnetic resonance imaging has been found superior to DSA in demonstrating the presence and the details of 
aneurysmal clot. ${ }^{19}$ It should be performed in patients with unruptured aneurysms presenting with ischemic symptoms. In this series, a thrombus was documented in two of the seven aneurysms measuring $10 \mathrm{~mm}$ or less. Since the blood flow may be of greater velocity in smaller aneurysms, higher shear forces may account for reduced clot formation and increased possibility of distal embolization. ${ }^{3}$ In addition, the aneurysm's location might also influence blood flow within the sac. In this series, most symptomatic aneurysms were located on the anterior circulation, namely in the internal carotid artery or the middle cerebral artery, as reported in previous series..$^{3,6,13,20}$ In addition to these hemodynamic factors contributing to the thromboembolic phenomenon, damage to the aneurysm's parietal wall such as micro-ruptures may trigger inflammatory processes leading to aneurysm clot formation. ${ }^{21}$

Until presently, no consensus exists regarding the indication to treat unruptured intracranial aneurysms. Site, size, and group specific risks of the natural history should be compared with site, size, and age-specific risks of treatment modality for each patient. ${ }^{5}$ In the prospective assessment of unruptured intracranial aneurysms, the five-year cumulative rupture rate for patients with no history of SAH with aneurysms located in the anterior circulation was $0 \%$ for aneurysms less than $7 \mathrm{~mm}$ and $2.6 \%$ in 7 $12 \mathrm{~mm} .{ }^{5}$ However, it has been stated that unruptured intracranial aneurysms presenting with neurologic symptoms such as cerebral ischemia may be under-represented in natural history studies. ${ }^{14}$ Indeed, patients with symptomatic unruptured aneurysms measuring less than $1 \mathrm{~cm}$ might have been preferentially treated in some series. ${ }^{14}$ The natural history of aneurysms presenting with ischemic events remains undefined., 4

Some authors have proposed antiplatelet medication which may inhibit platelet aggregation and activation within the aneurysmal sac and reduce the risk of ischemic events. . $^{3,20}$ Although the incidence of recurrent ischemic events has been reported to be low among patients treated with aspirin, recurrent symptoms after the first ischemic event has also been reported to be low without treatment. ${ }^{3}$ Nevertheless, antiplatelet medication might impair aneurysm wall healing favored by platelet derived mitogenic factors released within the platelet plug. ${ }^{22}$ The risk of subarachnoid hemorrhage while on antiplatelet medication is unknown. ${ }^{6}$

Aneurysm exclusion may be a preferred option because in addition to alleviating further ischemic events it prevents $\mathrm{SAH}$ from this aneurysm. ${ }^{6,8,13}$ However, clipping aneurysms presenting with thromboembolic events has been suggested at higher risk in comparison to asymptomatic aneurysms given the possibility of intraoperative thromboembolic events..$^{1,7}$ Postoperative cerebral infarctions may result either of dislodged thrombotic material embolizing to distal vessels or of extended thrombi from the aneurysmal sac into the parent artery lumen. In this series, three patients treated by surgical means presented a thromboembolic complication $(50 \%, 3 / 6)$. Of the five patients treated by endovascular means, one patient (Patient no. 4) $(20 \%$, $1 / 5$ ) presented a thromboembolic complication three months after re-treatment of a residual SCA aneurysm that had been coiled seven months earlier.

The three delayed complications were treated with antiplatelet medication. In the setting of an unruptured aneurysm with ischemic symptoms, administration of an antiplatelet medication prior to surgery has been suggested to inhibit the acute aggregation and activation of platelets and decrease thromboembolic complications..$^{21,23}$ Continuing antiplatelet treatment for the first year following aneurysm treatment could be of benefit since all ischemic symptoms occurred within the first year after treatment. ${ }^{3}$

To the authors' knowledge, coiling of aneurysms presenting with ischemic events has not been described in the literature. In this series, the unruptured aneurysms oriented towards endovascular treatment were either large (Patients 1 and 2) or located on the posterior circulation (Patients 3, 4, 5). All except Patient 5 had a partially thrombosed aneurysm. After discussion with the endovascular team, embolization was viewed as the safest treatment option for these patients. Patients treated endovascularly required a second embolization. Further studies are required to evaluate the efficacy and safety of coiling aneurysms that present with ischemic symptoms, specially for partially thrombosed aneurysms. Although the aneurysm recurrence is frequent for partially thrombosed aneurysms after coiling, the surgical risk for such lesion is significant. The best treatment for such aneurysms is not known.

It has been stated that the prognosis of unruptured aneurysms presenting with ischemic symptoms was good, regardless if the patient was treated medically or surgically. ${ }^{20}$ More recently, Nanda and colleagues compared the outcome of patients with unruptured cerebral aneurysms, including saccular and fusiform aneurysms, presenting with ischemic episodes to that of a group who presented in Hunt \& Hess grades 0 and 1 without ischemic symptoms. ${ }^{13}$ Their study group with ischemic episodes had a poorer prognosis. ${ }^{13}$ In our series, nine of the ten treated patients had a favorable outcome one year after aneurysm treatment.

There are some limitations to the present study. Although this is a retrospective study as most series assessing unruptured cerebral aneurysms presenting with ischemic events, all patients consecutively treated during the study period were included in the study if they answered the inclusion and not the exclusion criteria. The small number of patients is representative of how uncommon this presentation is in a tertiary neurosurgical center. Therefore the assessment is descriptive and no statistical analysis was possible.

In this series, aneurysms presenting with ischemic events were often small and located on the anterior circulation, features of aneurysms easily treatable either by endovascular or surgical means. However, thromboembolic events following treatment of such aneurysms were noteworthy. This information is relevant given the possible benign natural history in terms of stroke and risk of bleeding for some of these aneurysms. If the primary goal of treatment is to prevent recurrence of TIA rather than aneurysm rupture, then medical treatment alone might be the best management. However, if because of its size, location, and morphology, aneurysm rupture is a real concern, its exclusion may be justified. The decision must take into consideration the noteworthy rate of thromboembolic events following surgical treatment and the significant rate of incomplete treatment after embolization. 


\section{REFERENCES}

1. Antunes JL, Correll JW. Cerebral emboli from intracranial aneurysms. Surg Neurol. 1976;6:7-10.

2. Brownlee RD, Tranmer BI, Sevick RJ, Karmy G, Curry BJ. Spontaneous thrombosis of an unruptured anterior communicating artery aneurysm. An unusual cause of ischemic stroke. Stroke. 1995;26:1945-9.

3. Qureshi AI, Mohammad Y, Yahia AM, Luft AR, Sharma M, Tarmago RJ, et al. Ischemic events associated with unruptured intracranial aneurysms: multicenter clinical study and review of the literature. Neurosurgery. 2000;46:282-9.

4. Ecker RD, Hopkins LN. Natural history of unruptured intracranial aneurysms. Neurosurg Focus. 2004;17:1-5.

5. International Study of Unruptured Intracranial Aneurysms Investigators. [No authors listed]: Unruptured intracranial aneurysms: natural history, clinical outcome, and risks of surgical and endovascular treatment. Lancet. 2003;362:103-10.

6. Ohno K, Suzuki R, Masaoka H, Matsushima Y, Monma S, Inaba Y. Unruptured aneurysms in patients with transient ischemic attack or reversible ischemic neurological deficit. Report of eight cases. Clin Neurol Neurosurg. 1989;3:229-33.

7. Nagashima M, Nemoto M, Hadeishi H, Suzuki A, Yasui N. Unruptured aneurysms associated with ischaemic cerebrovascular diseases: surgical indication. Acta Neurochir (Wien). $1993 ; 124: 71-8$

8. Sakaki T, Kinugawa K, Tanigake T, Miyamoto S, Kyoi K, Utsumi S. Embolism from intracranial aneurysms. J Neurosurg. 1980; 53:300-4

9. Cohen MM, Hemalatha CP, D'Addario RT, Goldman HW. Embolization from a fusiform middle cerebral artery aneurysm. Stroke. 1980;11:158-61.

10. Sulter G, Steen C, De Keyser JS. Use of the Barthel index and modified Rankin scale in acute stroke trials. Stroke. 1999; 30:1538-41.

11. International Study of Unruptured Intracranial Aneurysms Investigators. [No authors listed]. Unruptured intracranial aneurysms - risk of rupture and risks of surgical intervention. $\mathrm{N}$ Engl J Med. 1998;339:1725-33.

12. Wiebers DO, Whisnant JP, Sundt TM Jr, O'Fallon WM. The significance of unruptured intracranial saccular aneurysms. J Neurosurg. 1987;66:23-9.
13. Nanda A, Vannemreddy PS. Cerebral ischemia as a presenting feature of intracranial aneurysms: a negative prognostic indicator in the management of aneurysms. Neurosurgery. 2006;58:831-7.

14. Friedman JA, Piepgras DG, Pichelmann MA, Hansen KK, Brown RD Jr, Wiebers DO. Small cerebral aneurysms presenting with symptoms other than rupture. Neurology. 2001;57:1212-6.

15. Eller TW. MRI demonstration of clot in a small unruptured aneurysm causing stroke. Case report. J Neurosurg. 1986;65: 411-2.

16. Hoffman WF, Wilson CB, Townsend JJ. Recurrent transient ischemic attacks secondary to an embolizing saccular middle cerebral artery aneurysm. Case report. J Neurosurg. 1979;51: 103-6.

17. Mehdorn HM, Chater NL, Townsend JJ, Darroch JD, Perkins RK, Lagger R. Giant aneurysm and cerebral ischemia. Surg Neurol. 1980;13:49-57.

18. Black SPW, German WJ. Observations on the relationship between the volume and the size of the orifice of experimental aneurysm. J Neurosurg. 1960;17:984-90.

19. Colpan ME, Sekerci Z, Hekimoglu B, Mogul DJJ. Computerassisted intraaneurysmal thrombus visualization. Neuroimaging. 2006;16:59-68

20. Przelomski MM, Fisher M, Davidson RI, Jones HR, Marcus EM. Unruptured intracranial aneurysm and transient focal cerebral ischemia: a follow-up study. Neurology. 1986;36:584-7.

21. Warin-Fresse K, Auffray-Calvier E, Desal H, Guillon B, De Kernaint-Gilly A. [Intracranial aneurysms presenting with ischemic stroke] [Article in French]. J Neuroradiol. 2006;33: 175-83.

22. Sutherland GR, King ME, Peerless SJ, Vezina WC, Brown GW, Chamberlain MJ. Platelet interaction within giant intracranial aneurysms. J Neurosurg. 1982;56:53-61.

23. Stewart RM, Samson D, Diehl J, Hinton R, Ditmore QM. Unruptured cerebral aneurysms presenting as recurrent transient neurologic deficits. Neurology. 1980;30:47-51. 